\title{
APLIKASI MOBILE UNTUK ENKRIPSI DATA GAMBAR MENGGUNAKAN KOMBINASI FUNGSI XOR DAN MODE OPERASI CBC
}

\author{
Jannatun Aliyah ${ }^{1^{*}}$ \\ Teknik Informatika Univertsitas Teknologi Sumbawa \\ email: jannatun.aliyah@uts.ac.id*
}

\begin{abstract}
Abstrak: Dalam tulisan ini memaparkan pembuatan aplikasi kriptografi dan mengimplementasikan model enkripsi pada data gambar. Tujuannya untuk keamanan pada penyimpanan file gambar. Proses enkripsi pada gambar akan menghasilkan hasil enkripsi yang dapat merahasiakan gambar. Sebaliknya, proses dekripsi akan mengembalikan gambar yang dirahasiakan tersebut kembali menjadi gambar aslinya. Metode yang digunakan dalam enkripsi dan dekripsi data gambar ini adalah kombinasi fungsi XOR dan mode operasi CBC (chipherblock Chaining). Dimana enkripsi yang dilakukan pertama kali dengan fungsi XOR kemudian dilanjutkan dengan enkripsi menggunakan mode operasi CBC. Mengkombinasikan fungsi XOR dengan mode operasi CBC bertujuan untuk meningkatkan keamanan data gambar, sehingga kriptanalis menjadi lebih sulit untuk menampilkan plaintext (gambar aslinya). Dalam pembuatan aplikasi CryptoImage ini menggunakan Netbeans yang merupakan salah satu aplikasi Integrated Development Environment (IDE) Java. Aplikasi ini digunakan khusus untuk mengembangkan program java. Dalam Netbeans ini, untuk aplikasi mobile menggunakan Java 2 Platform Micro Edition (J2ME). Ketersediaan fasilitas kriptografi pada platform J2ME ini memungkinkan kita untuk memanipulasi data-data agar kerahasiaannya bisa terjamin.
\end{abstract}

Kata Kunci : Informasi, Enkripsi, Dekripsi, Kunci

\begin{abstract}
In this paper explain how making the applications of cryptographic and implementing the encryption model in image or picture data. The goal for the security of the image file storage. The encryption process on the picture will produce result that can keep the image encryption. Conversely, the decryption process will restore image that is re-classified into the original image. The method used in the encryption and decryption of image data is a combination of the XOR function and the CBC operation mode (Chipherblock Chaining). Where the encryption is performed first with the XOR function was followed by encryption using the CBC operating mode. Combining the XOR function with the CBC operation mode is intended to increase the security of image data, so that it is more difficult for cryptanalysts to display plaintext (the original image or picture). In making this CryptoImage application using Netbeans which is one of the Java Integrated Development Environment (IDE) applications. This application is used specifically to develop a java programs. In this Netbeans, for mobile applications using Java 2 Platform Micro Edition (J2ME). The availability of cryptographic facilities on J2ME platform allows us to manipulate the data for confidentiality can be guaranteed.
\end{abstract}

Keywords : Information, Encryption, Decryption, Key

\section{PENDAHULUAN}

Kemajuan dan perkembangan teknologi informasi dewasa ini telah berpengaruh pada hampir semua aspek kehidupan manusia, terutama dalam hal berkomunikasi. Dengan adanya handphone (telepon genggam), komunikasi jarak jauh dapat dilakukan dengan cepat dan mudah. Namun, handphone tidak terlalu aman karena merupakan media komunikasi umum yang dapat digunakan oleh siapapun sehingga sangat rawan terhadap pencurian informasi oleh pihak-pihak yang tidak berhak mengetahui informasi tersebut. Oleh karena penggunaan handphone sangat luas yang umumnya mengandung informasi yang bersifat rahasia, maka keamanan informasi menjadi faktor utama yang harus dipenuhi. Informasi tersebut dapat berupa data gambar atau foto, video, audio, maupun berupa text.

Keamanan data merupakan hal yang sangat penting dalam menjaga kerahasiaan informasi terutama yang berisi informasi sensitif yang hanya boleh diketahui isinya oleh pihak yang berhak saja, apalagi jika pengirimannya dilakukan melalui jaringan publik, apabila data tersebut tidak diamankan terlebih dahulu, akan sangat mudah disadap dan diketahui isi informasinya oleh pihakpihak yang tidak memiliki wewenang.

Berbagai hal telah dilakukan untuk mendapatkan jaminan keamanan informasi rahasia ini. Salah satu cara yang digunakan adalah dengan menyandikan isi informasi menjadi suatu kode-kode yang tidak dimengerti sehingga apabila disadap maka akan kesulitan untuk mengetahui isi informasi yang sebenarnya. Cara tersebut biasa dikenal dengan sistem kriptografi yaitu dengan menyediakan isi informasi (plaintext) tersebut menjadi isi yang tidak dipahami melalui proses enkripsi (encipher), dan untuk memperoleh kembali informasi yang asli, dilakukan proses deskripsi (decipher).

Saat ini, banyak algoritma-algoritma kriptografi bermunculan sebagai teknik untuk mengamankan data. Berbagai macam algoritma tersebut diterapkan untuk tipe data yang berbeda dan memiliki tingkat keamanan yang berbeda pula.

Dalan Netbeans ini, untuk aplikasi mobile menggunakan Java 2 Platform, Micro Edition ( J2ME ). Ketersediaan fasilitas kriptografi pada platform J2ME ini memungkinkan kita untuk memanipulasi data-data agar kerahasiaannya bisa terjamin. 
Pengamanan informasi berupa gambar atau foto sangat penting karena sifatnya pribadi. Oleh karena itu, dibutuhkan suatu sistem untuk menjamin kerahasiaannya dengan pembuatan suatu program enkripsi data gambar menggunakan J2ME dengan Algoritma Fungsi XOR dan Mode Operasi CBC.

pembahasan mengenai pembuatan sebuah aplikasi kriptografi yang digunakan untuk menyandikan suatu data gambar, mencakup:

1. Pembuatan program dengan media pemrograman java khususnya J2ME

2. Aplikasi yang dibangun menggunakan metode enkripsi dan dekripsi dengan Algoritma Fungsi XOR dan mode Operasi CBC

3. Tidak mencakup cara penukaran kunci enkripsi dan dekripsi.

Adapun tujuan dari penelitian ini adalah untuk mengembangkan dan menambah pembendaharaan aplikasi mobile dalam dunia teknologi informasi yang semakin berkembang.

Aplikasi kriptografi ini dapat digunakan untuk

1. Mengatasi masalah pencurian informasi penting yaitu berupa data gambar atau foto.

2. Mencegah orang yang tidak berhak menerima pesan gambar atau foto rahasia atau penting dapat melihat informasi yang disampaikan pada pemiliknya.

\section{TINJAUAN PUSTAKA}

\section{Pemrograman Java}

\section{a. Bahasa Pemrograman Java}

Java adalah sebuah bahasa pemrograman komputer berbasiskan kepada Object Oriented Programming ( pemrograman berbasiskan objek ) yang sederhana dan tidak tergantung pada platform yang digunakan. Bahasa ini dikembangkan oleh Sun Microsystems dan memiliki banyak keunggulan, sederhana, ukurannya kecil, dan portable (dapat dipindah-pindahkan di antara bermacam platform dan sistem operasi).

\section{b. IDE Netbeans}

Netbeans sebagai IDE (Interface Development Environtment) ditujukan untuk memudahkan pemrograman interface. Memiliki fiture lebih baik dari software sepertinya yaitu Module Matisse GUI (Graphical User Interface). Memiliki fiture debugger untuk mengetahui dimana terjadi error. Memiliki fiture tooltip dimana dapat diketahui cara perbaikan untuk error. Berlisensikan Sun Public License atau open source.

\section{c. Java 2 Micro Edition}

Java 2 Micro Edition memiliki arsitektur yang unik, dibangun dengan desain modular yang memungkinkan aplikasi yang dibaut dapat di sesuaikan dengan keterbatasan perangkat telepon seluler. J2ME ini terdiri dari lapisan-lapisan yang terdapat di atas lapisan system operasi, dimana secara keseluruhan lapisan disebut CLDC ( Connected Limited Device Configuration ).
Keamanan pada J2ME merupakan salah satu hal yang sangat penting karena device J2ME mudah di bawa ke mana-mana (mobile). Dengan fasilitas mobile itu, maka sangat mungkin device tersebut hilang dan jatuh pada tangan yang salah. Hal tersebut akan menjadi bencana apabila terdapat data yang penting pada device tersebut. Kemungkinan tersebut akan menjadi lebih berkurang dengan adanya sistem keamanan yang memadai. Salah satunya adalah dengan enkripsi sebuah data.

\section{Bouncy Castle Cryptography API}

Pada website resminya disebutkan bahwa Bouncy Castle mwerupakan koleksi dari API yang digunakan dalam bidang kriptografi. Bouncy Castle memiliki API untuk bahasa pemrograman java dan C\#. Untuk keperluan kriptografi pada java mobile, API ini menyediakan versi lightweight. Kelas dasar untuk cipher didefinisikan dalam org.bouncycastle.crypto.engines yang di dalamnya mengimplementasikan operasi enkripsi dan dekripsi dari berbagai jenis cipher dasar, antara lain AES, BlowFish, Camelia, Casts, DES, Elgamal, Gost, dan masih banyak lagi.

Dalam API ini juga digunakan banyak mode operasi dalam enkripsi dan dekripsinya, salah satunya adalah mode $\mathrm{CBC}$. Mode $\mathrm{CBC}$ mendekripsikan bagaimana cipher harus memperlakukan rangkaian block ketika mengenkripsikan pesan multi block. Mode CBC merupakan mode yang memiliki kecepatan tinggi dan merupakan mode yang paling banyak diaplikasikan pada berbagai program.

\section{Diagram Model Use Case}

Pengertian use case sendiri adalah urutan langkah-langkah yang secara tindakan saling terkait (skenario) baik terotomatisasi maupun secara manual, untuk tujuan melengkapi satu tugas bisnis tunggal. Use case selalu di awali dengan sebuah notasi actor atau pelaku yang merupakan bagian dari luar system dan selalu berhubungan dengan system yang akan dibangun.

\section{Diagram Kelas}

Diagram kelas menunjukakan interaksi antara kelas di dalam system. Definisi kelas sendiri menurut Pressman adalah bagian dari desain sebuah system dan di dalam system eksis sebagai aksi eksekusi. Kelas menggambarkan himpunan obyek yang menggunakan atribut suatu system, sekaligus menawarkan layanan untuk memanipulasi keadaan tersebut (metoda/fungsi). Sedangkan diagram kelas menggambarkan struktur dan dekripsi class, $\mathrm{p}$ [ackage dan obyek beserta hubungan satu sama lain seperti containment, pewarisan, asosiasi, dan lain-lain

\section{Sequence Diagram}

Sequence diagram menggambarkan interaksi antar objek di dalam dan di sekitar sistem (termasuk pengguna, display, dan sebagainya) berupa message yang digambarkan terhadap waktu. Sequence diagram terdiri atar dimensi vertikal (waktu) dan dimensi horizontal (objek-objek yang terkait) 
Sequence diagram biasa digunakan untuk menggambarkan skenario atau rangkaian langkahlangkah yang dilakukan sebagai respons dari sebuah event untuk menghasilkan output tertentu. Diawali dari apa yang men-trigger aktivitas tersebut, proses dan perubahan apa saja yang terjadi secara internal dan output apa yang dihasilkan.

\section{Kriptografi}

\section{a. Definisi Kriptogafi}

Kriptogafi (cryptography) berasal dari Bahasa Yunani: "crypto" artinya "secret" (rahasia), sedangkan "graphein" artinya "writing" (tulisan). Jadi, kriptografi berarti "secret writing" (tulisan rahasia). Definisi yang dipakai di dalam buku-buku yang lama (sebelum tahun 1980-an) menyatakan bahwa kriptogafi adalah ilmu dan seni untuk menjaga kerahasiaan pesan dengan cara menyandikannya ke dalam bentuk yang tidak dapat dimengerti lagi maknanya

Menurut Sukmaaji dan Rianto (2008, h. 5), dijelaskan juga definisi Kriptografi sebagai ilmu untuk menjaga keamanan data dengan cara mengacak data sedemikian rupa, sehingga tidak bisa dibaca oleh pihak ketiga. Tentu saja data yang diacak harus bisa dikembalikan ke bentuk semula oleh pihak yang berwenang. Data yang ingin di acak biasanya disebut Teks Asli (Plain Text). Data di acak dengan menggunakan kunci enkripsi (Encryption Key). Proses pengacakan disebut Enkripsi (Encryption). Plain Text yang telah diacak disebut Cipher Text. Kemudian proses untuk mengembalikan Cipher Text ke Plain Text disebut Dekripsi (Decryption). Kunci yang digunakan pada tahap Dekripsi disebut Kunci Dekripsi (Decryption Key).

\section{b. Algoritma Kriptografi}

Algoritma kriptografi disebut juga cipher yaitu aturan untuk enchipering dan dechipering, atau fungsi matematika yang digunakan untuk enkripsi dan dekripsi. Beberapa cipher memerlukan algoritma yang berbeda untuk enciphering dan dechipering.

Konsep matematis yang mendasari algorotma kriptogafi adalah relasi antara dua buah himpunan yaitu himpunan yang berisi elemen-elemen plaintext dan himpunan yang berisi ciphertext. Enkripsi dan dekripsi merupakan fungsi yang memetakan elemenelemen yang memetakan kedua himpunan tersebut. Misalkan $\mathrm{P}$ menyatakan plaintext dan $\mathrm{C}$ menyatakan chipertext, maka fungsi enkripsi $\mathrm{E}$ memetakan $\mathrm{P}$ ke $\mathrm{C}$,

$$
E(P)=C
$$

Dan fungsi dekripsi D memetakan $\mathrm{C}$ ke $\mathrm{P}$,

$$
D(E(P))=P
$$

Kriptogafi modern mengatasi masalah enkripsi dan dekripsi dengan penggunaan kunci, yang dalam hal ini algoritma tidak lagi dirahasiakan, tetapi kunci harus dijaga kerahasiaannya. Kunci(key) adalah parameter yang digunakan untuk transformasi enchipering dan dechipering. Kunci biasanya berupa string atau deretan bilangan. Dengan menggunakan kunci K, maka fungsi enkripsi dan dekripsi dapat ditulis sebagai

$$
\mathrm{E}_{\mathrm{K}}(\mathrm{P})=\mathrm{C} \text { dan } \mathrm{DK}(\mathrm{C})=\mathrm{P}
$$

dan kedua fungsi ini memenuhi

$$
\mathrm{D}_{\mathrm{K}}\left(\mathrm{E}_{\mathrm{K}}(\mathrm{P})\right)=\mathrm{P}
$$

\section{c. Kriptografi dengan Fungsi XOR}

Berbeda dengan algoritma kriptografi visual pada umumnya, model ini menggunakan fungsi $X O R$ untuk algoritma enkripsi dan dekripsinya. Oleh karena itu, proses dekripsi tidak bisa dilakukan dengan hanya menumpuk transparansi.

Fungsi XOR dapat dijelaskan dalam table berikut.

Persamaan : $\mathrm{Z}=\mathrm{X} \oplus \mathrm{Y}$

Tabel 2.2.3.1.1. Fungsi XOR

\begin{tabular}{|c|c|c|}
\hline$X$ & $Y$ & $Z$ \\
\hline 0 & 0 & 0 \\
\hline 0 & 1 & 1 \\
\hline 1 & 0 & 1 \\
\hline 1 & 1 & 0 \\
\hline
\end{tabular}

Skema yang telah dikembangkan untuk kriptografi dengan fungsi XOR ialah $(2, n)$ dan $(n, n)$. Untuk skema $(n, n)$, dapat diperoleh hasil rekonstruksi atau dekripsi citra yang sempurna, sama dengan citra rahasia yang dienkripsi. Adapun untuk skema $(2, n)$, terdapat noise pada citra yang dihasilkan.

\section{d. Mode Operasi CBC}

CBC merupakan salah satu mode operasi cipher blok yang menerapkan umpan balik pada sebuah blok. Caranya, blok plainteks yang current di$X O R$-kan terlebih dahulu dengan blok cipherteks hasil enkripsi sebelumnya, selanjutnya hasil peng$X O R$-an ini masuk ke dalam fungsi enkripsi. Sedangkan pada proses dekripsi dilakukan dengan memasukkan blok cipherteks yang current ke fungsi dekripsi, kemudian meng-XOR-kan hasilnya dengan blok cipherteks sebelumnya. Dengan CBC, setiap blok cipherteks bergantung tidak hanya pada blok plainteksnya, tetapi juga pada seluruh blok plainteks sebelumnya. Gambar 2.2.3.2.1 memperlihatkan skema mode operasi CBC.

Pada mode CBC, blok-blok plainteks yang sama tidak menghasilkan blok-blok plainteks yang sama, sehingga kriptanalis menjadi lebih sulit. Hal ini menyebabkan mode CBC lebih banyak digunakan. Secara matematis, enkripsi dengan mode $C B C$ dinyatakan sebagai

dan dekripsi sebagai

$$
C_{i}=E_{K}\left(P_{i} \oplus C_{i-1}\right)
$$

$$
P_{i}=D_{K}\left(C_{i}\right) \oplus C_{i-1}
$$




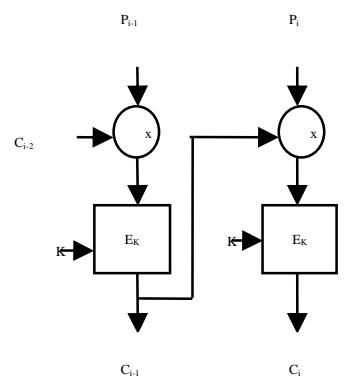

(a)Enkripsi

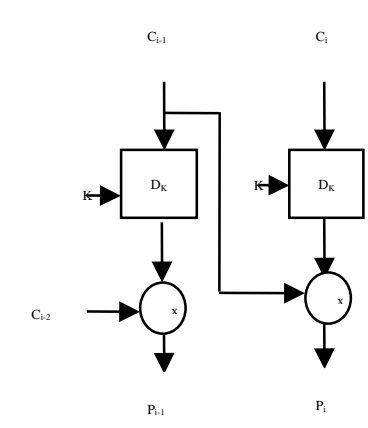

(b)Dekripsi
Gambar 6.a. Skema enkripsi dan dekripsi dengan Mode CBC

\section{METODOLOGI PENELITIAN}

Metode yang digunakan dalam penelitian ini antara lain:

1. Study Literatur (Tinjauan Pustaka)

Pencarian dan pengumpulan literatur yang mendukung untuk penulisan antara lain enkripsi dekripsi dan yang terkait dengan perangkat mobile.

2. Observasi penggunaan dan pembuatan program Pencarian akan kebutuhan alat serta file API apa saja untuk membangun program, permasalahan yang timbul, penanggulangan yang dibutuhkan saat pembuatan aplikasi.

3. Analisis dan Perancangan Sistem

Akan dilakukan analisis kebutuhan sistem yang akan dibangun dengan pembuatan progran enkripsi dan dekripsi.

4. Implementasi dan Uji Coba Sistem

Rancangan program dapat dinyatakan berhasil bila program tersebut dapat berjalan sesuai tujuan. Maka dilakukan implementasi dan uji coba program yang dibangun untuk memastikan kelayakan sistem.

\section{Kebutuhan Sistem}

Aplikasi CryptoImage merupakan sebuah system yang akan dibangun dengan beberapa komponen system, seperti data masukan (input), fungsi (method), data keluaran (output), dan antarmuka system (interface). Semua komponen tersebut akan saling berhubungan sehingga terbentuk sebuah system.

1. Data Masukan (input)

Data masukan merupakan data yang akan diolah oleh system sehingga menjadi data keluaran. Dalam aplikasi ini, akan menerima sebuah inputan berupa data gambar yang ada pada telepon genggam. Dengan beberapa fungsi input, data tersebut akan diubah menjadi data keluaran yang berupa data gambar yang terenkripsi pada proses enkripsi dan data gambar yang telah didekripsikan pada proses dekripsi.

2. Fungsi (method)
Fungsi merupakan aturan atau tata cara aplikasi mengolah data masukan berupa data gambar menjadi data keluaran berupa data gambar yang terenkripsi pada proses enkripsi dan data gambar yang telah didekripsikan pada proses dekripsi. Fungsi ini dibuat sehingga aplikasi hanya akan menjalankan perintah berdasarkan instruksi yang telah ditentukan.

3. Data Keluaran (Output)

Data keluaran merupakan data yang ditampilkan kepada pengguna system setelah dilakukan proses oleh fungsi-fungsi yang ada di dalam aplikasi. Data keluaran hanya akan ditampilkan setelah melalui proses yang telah di instruksikan dalam aplikasi. Data keluaran yang dihasilkan berupa data gambar yang terenkripsi pada proses enkripsi dan data gambar yang telah didekripsikan pada proses dekripsi.

4. Antarmuka (interface)

Aplikasi ini dibuat dengan tampilan Graphic User Interface (GUI) yang disesuaikan dengan kebutuhan, untuk memudahkan pengguna aplikasi dalam mengoperasikannya.

\section{HASIL DAN PEMBAHASAN}

\section{Aliran Kerja Analisa}

Aplikasi ini dibangun untuk memenuhi kebutuhan pengguna telepon genggam dalam menjaga keamanan data gambar yang tersimpan dalam memori telepon genggam agar terhindar dari pembajakan oleh pihak yang tidak diinginkan.

Aliran kerja analisa dari aplikasi CryptoImage ini meliputi fungsional modelling yaitu rancangan system yang akan dibangun ( use case Diagram), entity class modelling yaitu rancangan obyek (class Diagram), interaction modelling yaitu rancangan integrasi antar obyek (sequence Diagram).

\section{a. Fungsional Modeling}

Fungsional modelling dilakukan untuk mendekripsikan use case. Use case digunakan untuk melihat interaksi antara system dengan pengguna atau disebut actor.

Rancangan aplikasi yang akan dibangun disini dijelaskan siapa saja yang berperan ketikan aplikasi dijalankan dan apa saja yang dapat dilakukan. Gambar 1.a. menjelaskan mengenai business logic dari aplikasi. 


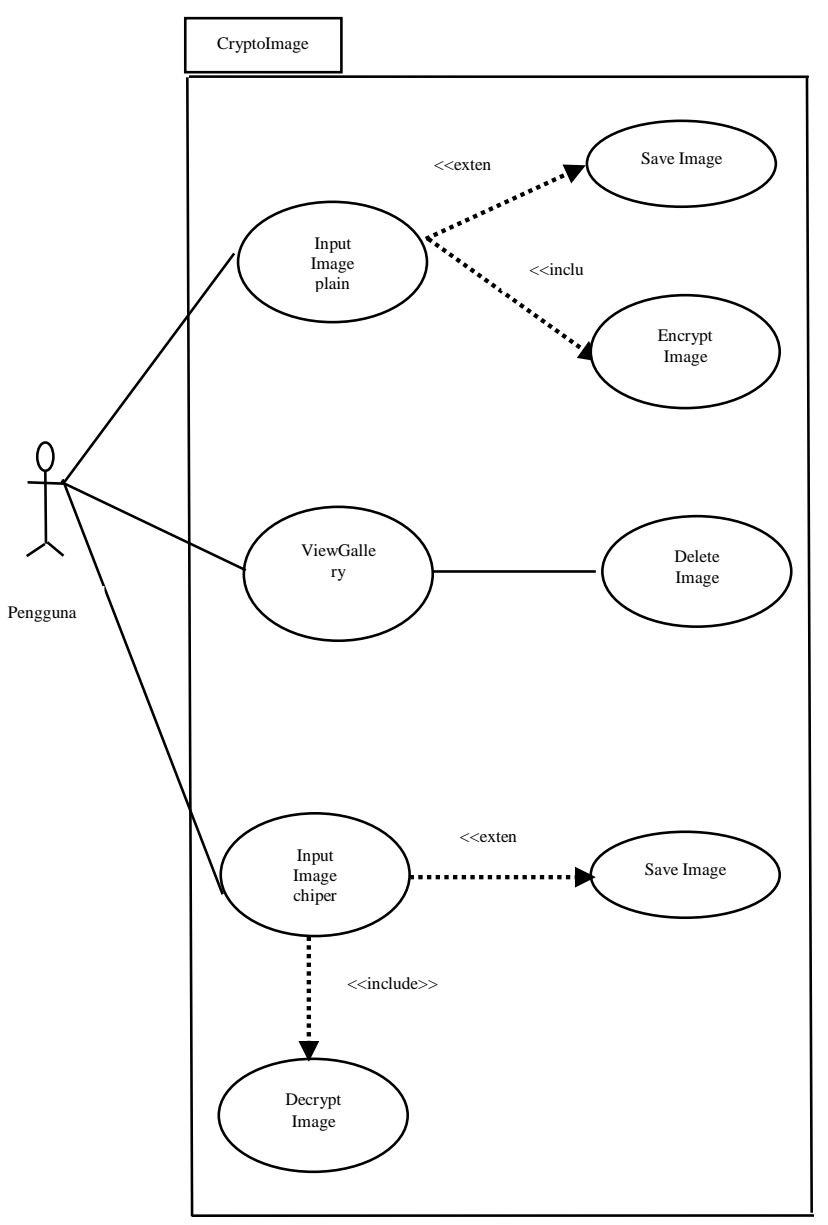

Gambar 1.a. Use Case Diagram

Aplikasi ini didesain hanya untuk satu pengguna dalan satu device. Dalam sebuah mobile device, aplikasi yang terinstal sebuah aplikasi saja dan tidak melibatkan aplikasi-aplikasi yang lain.

\section{b. Entity Class Modeling}

Aplikasi ini tersusun atas beberapa obyek penyusun yang menjadi dasar pembangunan aplikasi. Oyek-obyek tersebut saling menghubungkan antara obyek satu dengan lainnya, tergantung fungsi-fungsi dan method yang menghubungkan. Berikut gambar 1.b. rancangan obyek yang menyusun aplikasi.

\begin{tabular}{|c|c|c|}
\hline CryptoImage & \multirow[b]{3}{*}{$\begin{array}{l}\text { Crypto } \\
\text { Image }\end{array}$} & \multirow{2}{*}{$\begin{array}{l}\text { Gambar } \\
\text { Attributes }\end{array}$} \\
\hline \multirow{2}{*}{\begin{tabular}{l}
\multicolumn{1}{c}{ Attributes } \\
Private List PenyandianGambar \\
Private List Gallery \\
Private List Confirm
\end{tabular}} & & \\
\hline & & \multirow{3}{*}{ 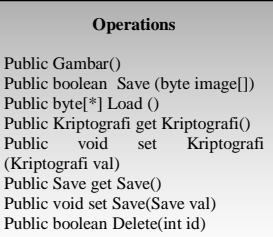 } \\
\hline Operations & & \\
\hline $\begin{array}{l}\text { Public Cryptolmage() } \\
\text { Public Confirm("Yes","No", } \\
\text { List.OK) } \\
\text { Public Gambar get Gambar() } \\
\text { Public void set Gambar(Gambar } \\
\text { val) }\end{array}$ & Gambar & \\
\hline Save & \multirow{6}{*}{ Save } & Kriptografi \\
\hline \multirow{3}{*}{\begin{tabular}{l}
\multicolumn{1}{c}{ Attributes } \\
Private RecordStore store \\
Private String storage \\
Private int amount
\end{tabular}} & & $\downarrow$ \\
\hline & & Kriptografi \\
\hline & & Attributes \\
\hline \multirow[b]{2}{*}{$\begin{array}{l}\quad \text { Operations } \\
\text { Save(String storage, int amount) } \\
\text { RecordStore get store() } \\
\text { Boolean open() } \\
\text { void close }() \\
\text { void Delete( }) \\
\text { void saveRecord() } \\
\text { StringreadRecord() }\end{array}$} & & Private String Kunci \\
\hline & & $\begin{array}{l}\text { Operations } \\
\text { Public Kriptografi(String Kunci) } \\
\text { Public String Enkripsi (byte image[]) } \\
\text { Public byte [*]Dekripsi (String } \\
\text { Chiper) } \\
\text { Public String get KunciO) } \\
\text { Public void set Kunci (String Kunci) }\end{array}$ \\
\hline
\end{tabular}

\section{Gambar 1.b. Class Diagram}

\section{c. Interaction Modeling}

Interaksi antar obyek dalam dan di sekitar system termasuk pengguna dan antarmuka pengguna dijelaskan dalam sequence diagram. Dari sequence diagram, alur aplikasi akan kelihatan, sehingga mempermudah programming agar lebih terarah.

Langkah-langkah menjalankan proses enkripsi pada aplikasi CryptoImage:

1. main menu ditampilkan,

2. pengguna memilih menu penyandian gambar atau gallery,

3. memilih menu penyandian gambar, pengguna diminta melakukan konfirmasi ("yes") dengan mengklik OK,

4. pengguna memilih encrypt untuk melakukan proses pencarian gambar, mengenkripsikan gambar kemudian menampilkan gambar yang terenkripsi,

5. pengguna mengklik save untuk melakukan penyimpanan data gambar terenkripsi,

6. klik cancel untuk mengakhiri proses dan kembali ke main menu,

7. memilih menu gallery untuk melihat data gambar yang telah tersimpan dalam memory,

Apabila konfirmasi("No"), maka akan kembali ke main menu dan pengguna dapat memilih menu pada main menu.

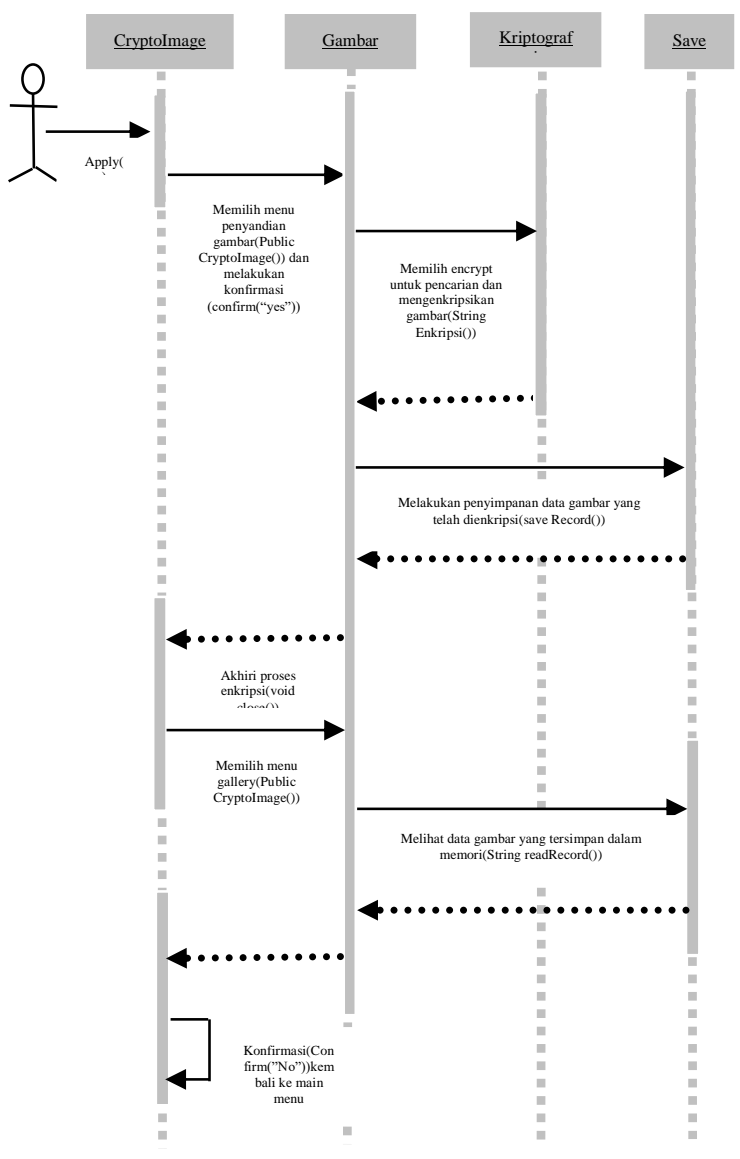




\section{Gambar 1.c. Sequence Diagram Enkripsi gambar}

Untuk melakukan proses dekripsi gambar sama dengan proses enkripsi. Langkah-langkah menjalankan proses dekripsi pada aplikasi CryptoImage:

1. main menu ditampilkan,

2. pengguna memilih menu penyandian gambar atau gallery,

3. memilih menu penyandian gambar, pengguna diminta melakukan konfirmasi ("yes") dengan mengklik OK,

4. pengguna memilih decrypt untuk melakukan proses pencarian gambar, mendekripsikan gambar kemudian menampilkan gambar yang telah didekripsi,

5. pengguna mengklik save untuk melakukan penyimpanan data gambar yang telah didekripsi,

6. klik cancel untuk mengakhiri proses dan kembali ke main menu,

7. memilih menu gallery untuk melihat data gambar yang telah tersimpan dalam memory,

Apabila konfirmasi("No"), maka akan kembali ke main menu dan pengguna dapat memilih menu pada main menu

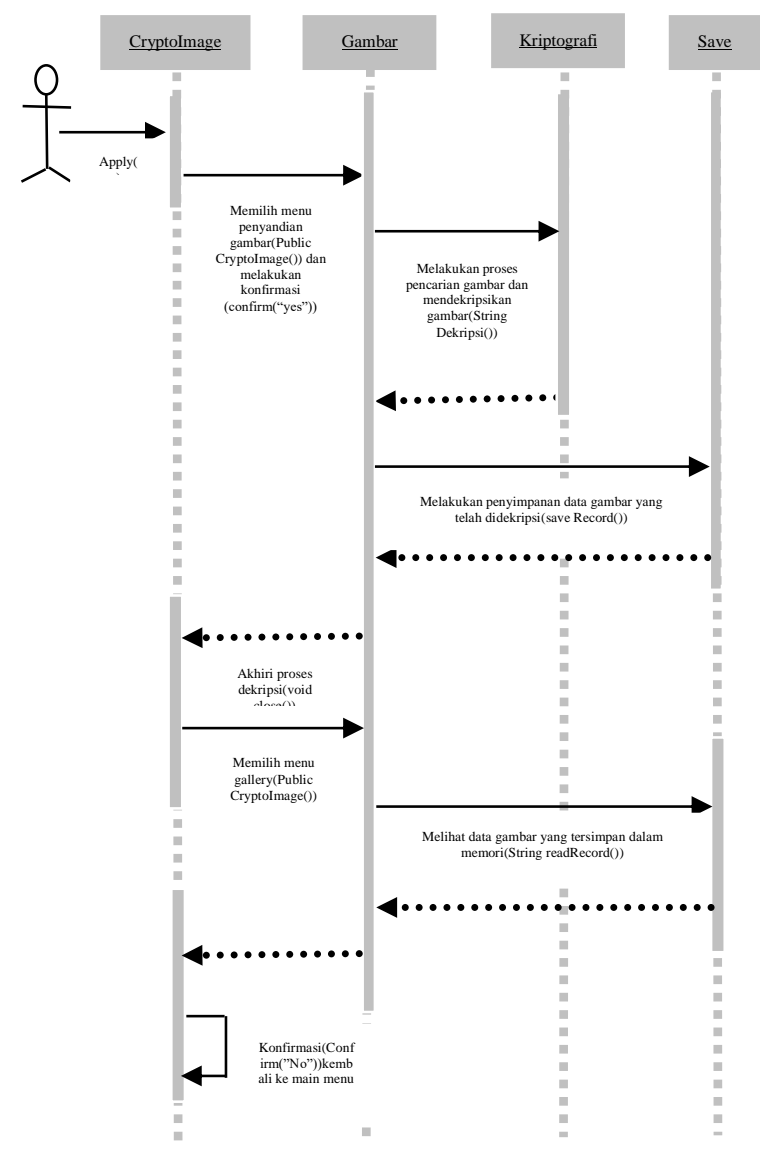

Gambar 1.d Sequence Diagram Dekripsi gambar

\section{Implementasi Antar Muka}

Untuk implementasi antar muka, aplikasi akan diuji dengan menggunakan dua buah emulator yaitu Sun Java(TM) Wireless Toolkit 2.5.2 for CLDC dan S80 3rd Edition SDK FP 1 for MIDP. Hal ini bertujuan untuk memperoleh data-data yang akurat mengenai aplikasi baik pada tahap pengkodean maupun uji coba sebelum digunakan pada telepon genggam yang sebenarnya.

Tujuan dilakukannya pengujian terhadap suatu perangkat lunak adalah untuk mengetahui apakah aplikasi telah berjalan sesuai dengan rancangan pembuatan aplikasi. Pengujian aplikasi ini dilakukan dengan menguji apakah aplikasi berjalan sesuai dengan sasaran aplikasi yaitu skenario setiap use case yang telah dibuat. Pengujian dilakukan pada dua buah lingkungan yang berbeda yaitu yang pertama dilakukan menggunakan emulator pada computer desktop dan yang kedua dilakukan pada telepon genggam yang sesungguhnya.

Pengujian pertama menggunakan emulator agar memudahkan dalam mendeteksi kesalahan pada tahap pengkodean dan mem-build aplikasi. Jika aplikasi telah berjalan sesuai dengan perancangan, maka tingkat kesalahan dapat diminimalkan. Pada tahap pengujian ini aplikasi bisa berjalan tanpa perlu memikirkan sumber daya.

\section{a. Antar Muka Form}

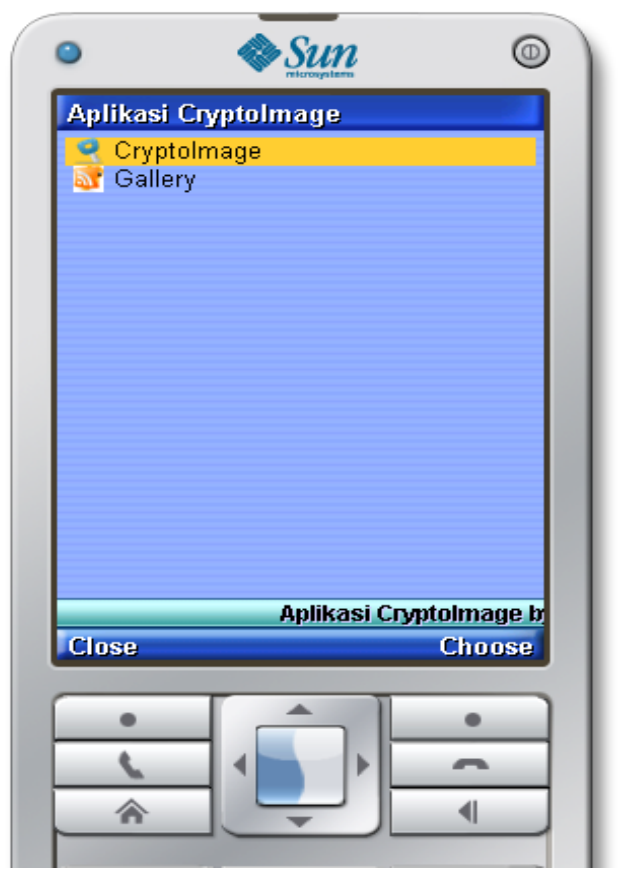

Gambar 2.a. Tampilan Antar Muka Menu Utama

Tampilan form menu utama sebagai MainMIDlet untuk mulai menjalankan aplikasi. Pilihan list Penyandian Gambar merupakan menu untuk melakukan proses enkripsi dan dekripsi gambar. Sementara menu Gallery merupakan tempat penyimpanan data gambar. 


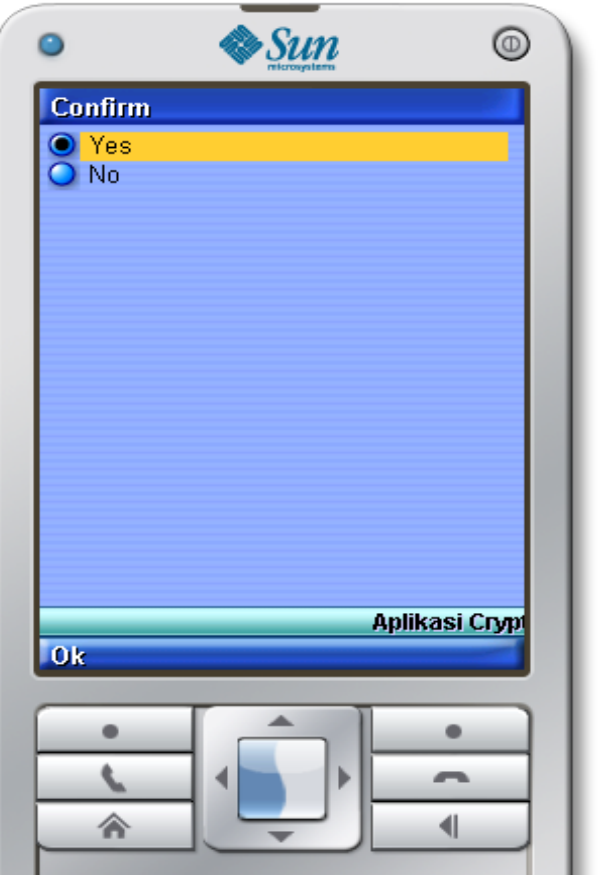

Gambar 2.b. Tampilan Antar Muka Confirm

Tampilan form confirm sebagai konfirmasi bahwa pengguna akan melakukan penyandian gambar yaitu melakukan proses enkripsi dan dekripsi gambar. Apabila konfirmasi gagal dilakukan maka akan kembali ke menu utama

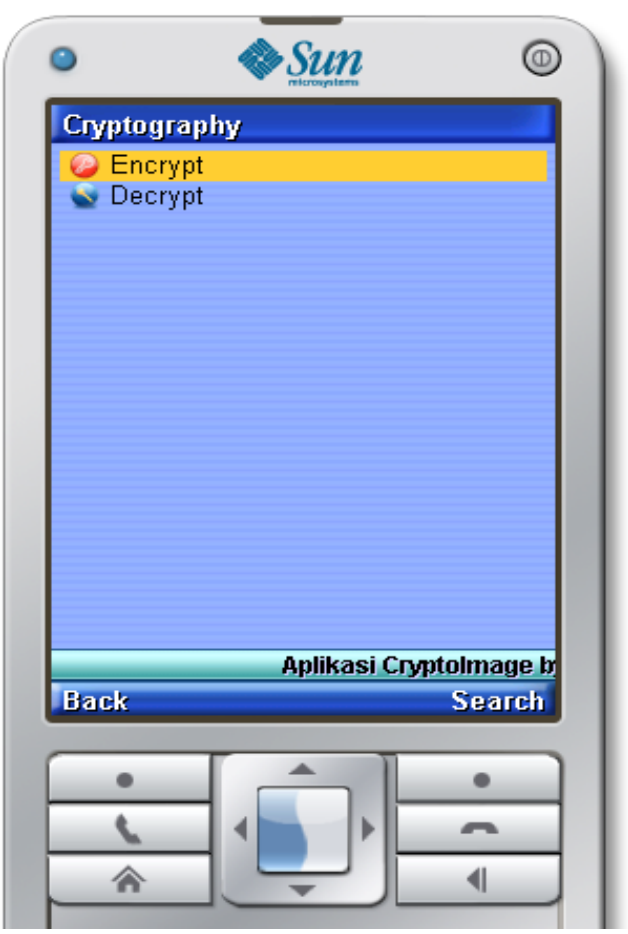

Gambar 2.c. Tampilan Antar Muka Cryptography

Tampilan form ini terdapat dua buah list yang merupakan menu untuk melakukan proses enkripsi dan dekripsi gambar
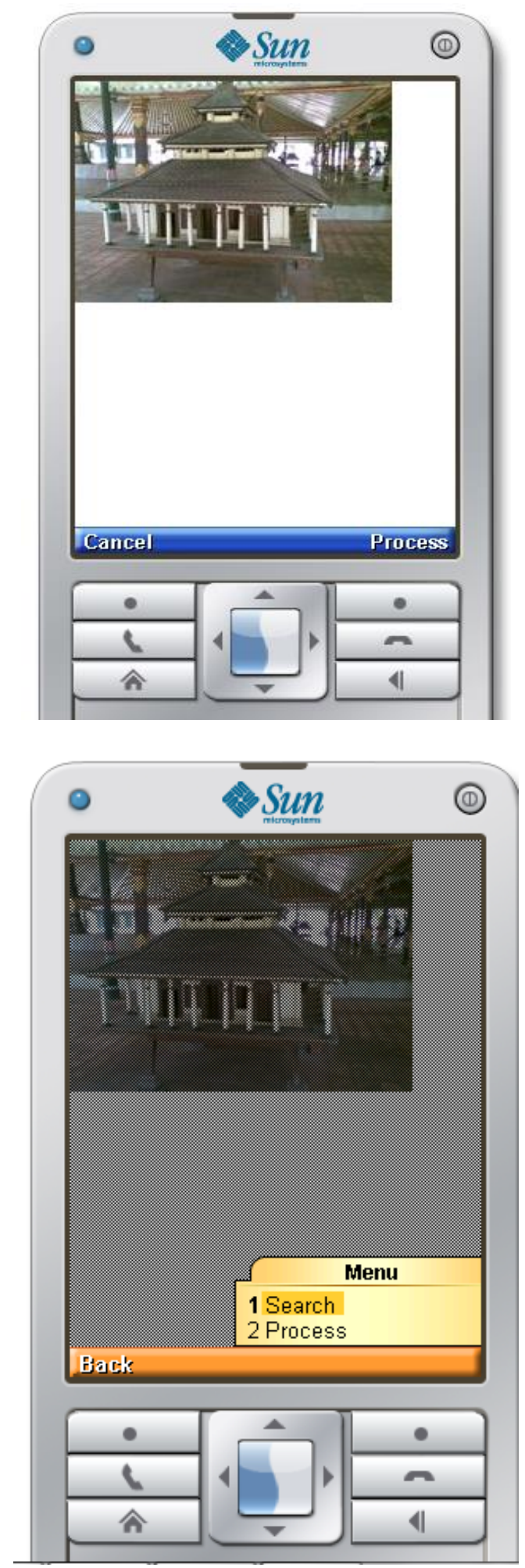

Gambar 2.d. Tampilan Antar Muka Form Encrypt

Tampilan form encrypt, menampilkan gambar yang akan dienkripsi. Gambar ditampilakn dengan menggunakan canvas. Tombol prosess digunakan untuk mulai melakukan enkripsi gambar dan akan tersimpan dalam RMS. 


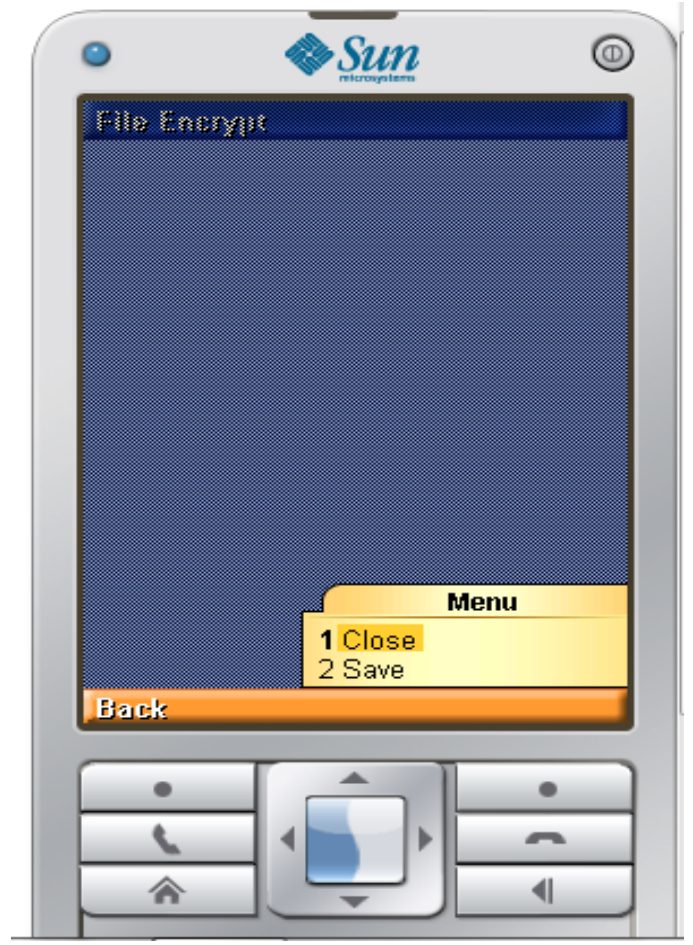

Gambar 2.d. Tampilan Antar Muka Form File Encrypt

Tampilan form file encrypt, akan dilakukan penyimpanan gambar yang telah dienkripsi. Pada form ini juga dapat dilakukan dekripsi atau mengembalikan gambar ke dalam bentuk semula atau plain.

\section{Aplikasi CryptoImage}

Aplikasi CryptoImage memiliki delapan kelas. Semua kelas memiliki fungsi masing-masing antara lain:

\begin{tabular}{|c|l|l|l|}
\hline No & Nama Kelas & $\begin{array}{c}\text { File } \\
\text { Source } \\
\text { Code }\end{array}$ & \multicolumn{1}{c|}{ Fungsi } \\
\hline 1. & MainMidlet & $\begin{array}{l}\text { CryptoIma } \\
\text { ge.java }\end{array}$ & $\begin{array}{l}\text { Kelas utama untuk menjalankan method } \\
\text { StartApp(), PauseApp(), DestroyApp() }\end{array}$ \\
\hline 2. & Galeri & $\begin{array}{l}\text { Gallery.jav } \\
\text { a }\end{array}$ & $\begin{array}{l}\text { Berisi data gambar yang terdapat dalam } \\
\text { database (RMS) }\end{array}$ \\
\hline 3. & $\begin{array}{l}\text { Enkri } \\
\text { psi }\end{array}$ & $\begin{array}{l}\text { Enkripsi.ja } \\
\text { va }\end{array}$ & $\begin{array}{l}\text { Berisi tampilan data gambar yang telah } \\
\text { dienkripsi }\end{array}$ \\
\hline 4. & Dekripsi & $\begin{array}{l}\text { Dekripsi.ja } \\
\text { va }\end{array}$ & $\begin{array}{l}\text { Berisi tampilan data gambar yang telah } \\
\text { didekripsi }\end{array}$ \\
\hline 5. & Menu Utama & $\begin{array}{l}\text { MenuUta } \\
\text { ma.java }\end{array}$ & Berisi pilihan menu enkripsi dan dekripsi \\
\hline 6. & Save & Save.java & $\begin{array}{l}\text { Berisi beberapa method yang selalu } \\
\text { digunakan aplikasi yaitu method Save(), } \\
\text { Delete(int id) dari RMS }\end{array}$ \\
\hline 7. & Kriptografi & $\begin{array}{l}\text { Kriptografi } \\
\text { java }\end{array}$ & $\begin{array}{l}\text { Berisi dua buah method yaitu method } \\
\text { enkripsi(byte[*]Image) dan method } \\
\text { dekripsi() }\end{array}$ \\
\hline 8. & Gambar & G & $\begin{array}{l}\text { Berisi method yang akan menghubungkan } \\
\text { antara kelas interface dengan kelas } \\
\text { Kriptografi.java dan Save.java }\end{array}$ \\
\hline
\end{tabular}

Tabel 3.a. Kelas Aplikasi CryptoImage

\section{Instalasi MIDlet ke Dalam Telepon Seluler}

Terdapat beberapa cara untuk melakukan instalasi terhadap aplikasi MIDlet yang dibuat ke dalam telepon seluler (handphone) : infrared, bluetooth, maupun serial (kabel data). Berikut langkah yang perlu dilakukan: a. Untuk membuat file JAR pilih menu Project Package | Create Package dari jendela Ktoolbar, maka file JAR akan terbentuk pada direktori bin. Untuk memindahkan MIDlet ke ponsel yang sesungguhnya dapat digunakan koneksi bluetooth, GPRS, ataupun inframerah. Dalam prakteknya, ada beberapa ponsel yang hanya membutuhkan file JAR saja, namun ada pula yang membutuhkan file JAD dan JAR dalam proses instalasi aplikasi pada ponsel.

b. Dari dalam handphone, pilih file JAR/JAD yang baru saja dicopy. Secara otomatis, AMS (Application Management Software) akan memunculkan menu "Install" pada layar handphone. Pilih menu tersebut untuk melalui proses instalasi. Sampai disini user sudah dapat menjalankan aplikasi tersebut dari handphone.

\section{Uji Coba Aplikasi}

Pengujian kedua yaitu pada lingkungan yang sebenarnya dalam hal ini adalah mobile phone. Pada tahap ini, hal utama yang sering menjadi kendala adalah menejemen memory. Karena memory menjadi salah satu pertimbangan utama dalam membangun aplikasi yang berjalan pada ponsel. Pengujian pada tahap pertama maupun tahap kedua diharapkan mendapatkan hasil yang sama. Uji coba aplikasi berguna dilakukan untuk menganalisa kelayakan sistem yang dibangun.

Pengujian pada imulator dan telepon seluler terdapat perbedaan pada tombol. Pada imulator, tombol dapat dipilih langsung ketika akan melakukan eksekusi. Akan tetapi pada telepon seluler, pengguna harus memilih menu pilihan untuk mengetahui proses eksekusi selanjutnya.

File gambar yang digunakan pada waktu uji coba adalah file gambar dengan ekstensi file .jpeg, .png, dan .gif. Hasil uji coba dengan file gambar dengan ekstensi file .jpeg dan .png didapatkan hasil enkripsi yang baik sementara untuk file gambar dengan ekstensi file .gif didapatkan hasil yang kurang baik.

\section{KESIMPULAN DAN SARAN}

\section{Kesimpulan}

Dari hasil pembuatan dan pengujian diambil kesimpulan bahwa :

1. Program dapat dijalankan pada emulator yang telah disediakan.

2. Program dapat dijalankan pada device / alat mobile device yang sesungguhnya.

3. Terdapat perbedaan tampilan pilihan untuk melakukan proses eksekusi pada aplikasi.

4. File gambar yang digunakan pada waktu uji coba adalah file gambar dengan ekstensi file .jpeg, .png, dan .gif.

5. Hasil uji coba dengan file gambar dengan ekstensi file .jpeg dan .png didapatkan hasil enkripsi yang baik sementara untuk file gambar dengan ekstensi file .gif didapatkan hasil yang kurang baik. 
6. Keterbatasan emulator dan fasilitas lingkungan pengembang untuk platform J2ME menyebabkan sulitnya proses debugging. IDE Netbeans telah menyediakan sebuah debugger yang terintegrasi, namun ketika dijalankan menggunakan emulator yang lain, belum tentu support untuk testing program ini.

7. Agar aplikasi ini dapat berjalan pada device mobile sesuai dengan yang diharapkan, maka pada saat uji coba digunakan imulator java wireless toolkit 2.5.2 for CLDC dan imulator dari IDE Neatbeans.

\section{Saran}

Setelah membangun aplikasi ini, didapatkan beberapa saran penting dalam upaya pengembangan aplikasi ini nantinya dan dalam upaya pengembangan J2ME.

1. Pengembangan Aplikasi

Jika nanti ada yang mengembangkan aplikasi CryptoImage ini, ada beberapa hal yang perlu diperhatikan:

a. Untuk memudahkan anda mendebug, gunakan saja emulator asli bawaan IDE Netbeans karena sudah mendukung penggunaan gambar. Aplikasi ini apabila menggunakan gambar, layar akan menyesuaikan pada emulator dan mobile phone.

b. Untuk menyempurnakan aplikasi CryptoImage, pengembang dapat menggunakan xml untuk membuat tampilan lebih menarik.

2. Untuk pengembangan lingkungan $\mathrm{J} 2 \mathrm{ME}$

a. Mendefinisikan metode dan kelas apa yang tersedia dalam platform tertentu.

b. Hindari alokasi dan dealokasi data yang berulang-ulang

\section{DAFTAR PUSTAKA}

[1] Aditya Hartanto, Antonius, 2004, Pemrograman Mobile Java dengan MIDP 2.0, Yogyakarta, Penerbit Andi.

[2] Ariyus, Doni, 2008, Kriptografi, Yogyakarta, Penerbit Andi.

[3] Dharwiyanti, S., dan Wahono, R.S., 2006, Pengantar Unified Modelling Language (UML), http://www.ilmukomputer.org/wp.content.

[4] Hakim, R., dan Sutarto, 2009, Mastering Java ${ }^{T M}$, Jakarta, Elex Media Komputindo.

[5] Introduction to UML With Microsoft Visio, http://angew.info/files/Tutorial_UML/Model_Worksh op UML bab2.pdf.

[6] JENI, Pengenalan Bahasa Java, http://poss.ipb.ac.id/files/JENI Intro1 Bab02 Pengen alan_Bahasa_Java.pdf.

[7] Kisjantoro, A.I., 2007, Java ME, http://Kur2003.if.itb.ac.id/files/IF 2281 J2ME MIDP .pdf.

[8] Knudsen, J., 2003, Wireless Java Developing with J2ME, Second Edition, Apress, Barkeley.
[9] Pengantar Kriptografi, http://www.informatika.org/ rinaldi/Buku/Kriptografi/ Bab-1_Pengantar_Kriptografi.pdf.

[10] Raharjo, B., dkk, 2007, Tuntunan Pemrograman Java untuk Handphone, Bandung, Informatika.

[11] Setianto, Dwi, 2006, Panduan Lengkap Pemrograman Celluler Device dengan J2ME, Yogyakarta, Ardana Media. 